\title{
SWOT ANALYSIS OF EASTERN MEDICINE DEVELOPMENTS IN BULGARIA
}

\author{
Desislava Vankova \\ Department of Social Medicine and Healthcare Organisation, Faculty of Public Health, \\ Medical University of Varna
}

\begin{abstract}
Geographically, Bulgaria is situated in the heart of the Balkans, bridging Western European and Eastern (Asian) cultures. In this article, Eastern Medicine (EM) developments in Bulgaria are investigated. EM is a heterogeneous concept that comprises many curing methods (focused therapies), or complete medical therapeutic systems (like Traditional Chinese Medicine, Ayurveda, Tibetan medicine), which are native for Asia and applied worldwide. In order to explore the current status, needs and expectations in the field of EM in Bulgaria, we have carried out the classical SWOT analysis (Strengths, Weaknesses, Opportunities and Threats). Contrary to popular belief, SWOT analyses must follow strict guidelines in order to be a credible instrument of change. We therefore describe the theoretical backgrounds and rationale of such analysis before proceeding to its application to the Bulgarian EM situation. Our analysis reveals that there are both strengths and opportunities for the modern developments of EM in Bulgaria. They must, however, outweigh the weaknesses and threats to such a development. In our view, increased international collaboration, more awareness of the EM effectiveness and public health benefits shall enhance the chances of EM to be fluently integrated in the Bulgarian national health care system. The development of more outward-looking public health stakeholders could enhance the chances of the rapid establishment of modern schools for EM in the country.
\end{abstract}

Keywords: Bulgaria, Eastern medicine, medical education, SWOT analysis

\section{INTRODUCTION}

Geographically, Bulgaria is situated in the heart of the Balkans, bridging Western European and Eastern (Asian) cultures. Historically, Bulgaria is an ancient country with rich heritage in medicinal practices (1-4). Nowadays, Bulgarian health care is a typical modern (conventional, orthodox, West-

\footnotetext{
Address for correspondence:

Desislava Vankova

Faculty of Public Health

Medical University of Varna

55 Marin Drinov St

9002 Varna

e-mail:vanko07@gmail.com
}

Received: October 31, 2018

Accepted: November 12, 2018 ern or allopathic) care. The place of the Eastern Medicine (EM) methods in the country is outside conventional health care, which means: not publicly funded; no relevant national data on the prevalence of use and provision of such care. However, in many countries with highly developed healthcare systems, like Switzerland, France, Italy, UK, and Germany, some EM therapies are being adopted by the conventional health care (5).

\section{AIM}

In this article, EM developments in Bulgaria will be investigated. The aim is twofold. First, to provide a framework for analysis of the EM domain in Bulgaria. Methodologically, the classical SWOT (Strengths, Opportunities, Weaknesses and Threats) analysis is selected as a tool for the inquiry. Second, a SWOT analysis of the EM domain in Bulgaria will 
be presented and new strategies proposed. A balance in the analysis will be sought between the needs and expectations of national and international key stakeholders. Key stakeholders are those who can significantly influence and have formal institutional objectives or are important to the success of a project/field development/initiative, etc. (6).

The presented analysis is inspired by the lectures and practical teachings of Dr Fenny Yunita during the training course in Traditional Indonesian Medicine and Acupuncture (7). Further, this analysis is a natural continuation of the recently published online article (8) exploring the Eastern-Western medicine cooperation in a Bulgarian context.

\section{DEFINING THE EM DOMAIN IN BULGARIA}

EM is a heterogeneous concept that comprises many curing methods (focused therapies), or complete medical therapeutic systems, which originated in Asia and are applied worldwide. The main EM therapeutic systems, native for the Asian continent are:

$\diamond$ Traditional Chinese Medicine (TCM) originated in ancient China more than 2,500 years ago. TCM lies on the solid cultural and philosophical backgrounds of Taoism and Confucianism (9). TCM encompasses many different practices, including acupuncture, moxibustion (burning an herb above the skin to apply heat to acupuncture points), Chinese herbal medicine, Chinese therapeutic massage, gua sha (a rubbing therapy), dietary therapy, and tai chi and qigong (practices that combine specific movements or postures, coordinated breathing, and mental focus).

$\diamond$ Ayurveda (the 'science of life') is the traditional medicinal system native to India. It uses specific methods for achieving physical, mental and spiritual health and well-being. Ayurveda focuses on prevention and as a holistic approach to therapy is practiced in Europe, where several of its methods, such as the use of herbs, massage, and yoga are applied on their own as a form of complementary or alternative methods of prophylactics or treatment. $\diamond$ Tibetan Medicine, Sowa Rigpa (the 'science of healing'), is a system of traditional medicine native to Tibet (applied in regions of India, Nepal, Bhutan, Mongolia, Himalayan regions). It is a complete medical system based on the Buddhist philosophy. Tibetan Medicine aims to balance the three aspects of life: body, energy and mind by internal and external therapies, and by the introduction of health promoting self-administered exercises. It is a holistic approach to diagnosis and recommends lifestyle and dietary modification, prescribes medicines composed of natural materials (e.g. herbs and minerals) and employs physical therapies to treat illness.

Traditional systems of medicine also exist in other East and South Asian countries, including Japan (where the traditional herbal medicine is called Kampo), Korea, Vietnam, Indonesia (Indonesian traditional medicine is called Jamu) (9). Some of these systems have been strongly influenced by TCM, Ayurveda or Tibetan Medicine, but each has developed specific traditions and characteristics of its own.

\section{DEFINING THE SWOT FRAME}

In endeavoring to explore needs and expectations in the field of EM in Bulgaria we have chosen the practical SWOT analysis frame (10).

SWOT analysis is a powerful and simple management tool. The traditional settings for SWOT analyses have been businesses (11). Unlike many business planning techniques, the SWOT analysis is an approach that is primarily intuitive and judgmental, rather than mechanistic and measurable (12). The primary objective of the SWOT analysis is to assess the organization's strategic position vis-à-vis changes in its external environment.

The SWOT analysis embodies the exploration of the environment outside the organization to identify both opportunities and threats and the environment inside the organization to identify both strengths and weaknesses. Basically, 'outside' factors are those that are not under organizational control, while 'inside' factors are controlled by the organization at hand (13). Opportunities and threats are usually (though not necessarily) more about the future than the present, while strengths and weaknesses are about the present and not the future (14). 
SWOT's versatility and simplicity should not be confused with "anything goes". In fact, for maximum benefit, SWOT demands rigorous discipline and sometimes tedious iteration. Therefore, a simple, yet powerful, framework of four rounds of data collection and analysis of external and internal factors is adapted $(15,16)$.

SWOT Analysis, Round 1: Identifying Opportunities and Threats

The purpose here is to explore the environment outside the organization in order to identify the opportunities and threats the organization faces and to identify key success factors (17). Two categories of external environments are distinguished: international and national, which are composed of political, economic and sociocultural factors.

SWOT Analysis, Round 2: Identifying Strengths and Weaknesses

The demands of the external environment must be matched with the resources of the organization/domain, which are identified as strengths and weaknesses (namely those aspects of the organization that can help or hinder the accomplishment of its mission).

The aim of the first two rounds is to generate a simple compilation of lists providing useful information for the following step.

SWOT Analysis, Round 3: Mapping Interactions \& Strategy Classification

In the third round starts the clarification of the salient issues using a two-by-two matrix. The basic SWOT matrix is extracted from Weihrich's (1982) TOWS model. Thus, analysts develop a graphical portrayal or a "map" of their SWOT - external opportunities and internal strengths related to each other are noted into upper left quadrant; threats and strengths that are related are noted in the bottom left quadrant, and so on. The identified combinations of relationships may, in turn, become the basic for key success strategies formulation. Based on the interactions mapped SWOT identifies four classes of strategic issues labeled as follows: SO - Maxi-Maxi or Comparative Advantage, WO - Mini-Maxi or Investment/Divestment, ST - Maxi-Mini or Mobilization, and WT - Mini-Mini or Damage Control strategy (Fig. 1).

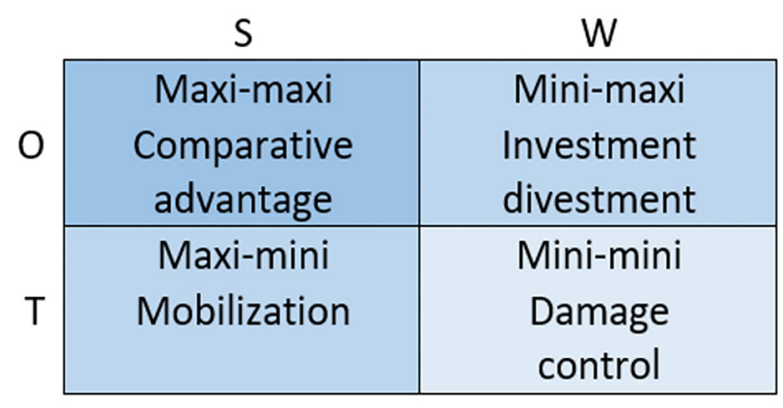

Fig. 1. A conceptual model - the SWOT map of strategy classification [modified from Weihrich, 1982]

The bottom right quadrant presents situations in which decision-makers' best opportunity is to engage in strategies of 'damage control'. The situation may be very damaging, even catastrophic. The bottom left quadrant directs attention to a strategy of 'mobilization'. If the organization is strong, it can choose the strategy of managing its environment by transforming certain threats into opportunities for its long-term advantage. Thus, the generic issue in the mobilization cell is the following: How can the organization mobilize its strengths to avert a perceived threat or even transform this threat into an opportunity? In the upper right quadrant, decision-makers face an ambiguous set of circumstances. They are presented with potentially promising opportunities that, at present, are not well positioned to exploit; there is a final opportunity of holding onto the status quo by neither investing nor divesting. Finally, the upper left quadrant highlights for decision-makers the strategic choice in which the organization is in a strong position, by virtue of its strengths, to capitalize on certain perceived opportunities. Thus, in the lexicon of strategic planning, the agency appears to have a 'comparative advantage' for future development. In generic terms, the comparative advantage issue facing decision-makers is the following: How can the agency leverage its strengths to achieve or enhance its comparative advantage, thereby capitalizing on a perceived opportunity? (16). The framing of strategic issues is the critical component in health care management. It can provide public health professionals and policy makers in Bulgaria with the opportunity to seize the initiative rather than to wait. In this article, SWOT's versatility and simplicity will be used for analyzing the issue at stake: EM domain developments in Bulgaria. 
DEVELOPMENTS OF THE EM DOMAIN IN BULGARIA - SWOT APPLICATION

Round 1: Identifying Opportunities and Threats of the EM External Environment

To collect data on the various external factors, related to EM in Bulgaria is, to say the least, a difficult task. The factors of the external environment can be classified into international and national.

Opportunities of the external environment for EM developments in Bulgaria:

\section{International factors for EM developments in Bulgaria}

Worldwide, EM therapeutic methods have long traditions and strong professional representation. EM care is a rapidly growing part of the healthcare economy, used by significant numbers of people and patients. These dynamic international developments could be summarized as international opportunities such as:

$\diamond$ In the second half of the previous century the World Health Organisation (WHO) admitted that the use of traditional or EM has expanded and gained popularity not only in the primary health care for the poor in the developing countries, but also in the countries where the conventional medicine is predominant in the national health care system. As a result, WHO developed a series of guidelines such as Guidelines for the Assessment of Herbal Medicines, Guidelines for the Assessment of Clinical Research in Acupuncture, General Guidelines for Methodologies on Research and Development of Traditional Medicine, etc. (18). All these documents have supported the tremendous expansion of EM and contribute to the introduction of standards in the field. WHO recommended the development of regional policies and legislation, which regulates the EM-development worldwide (19).

$\diamond$ The European Parliament supported the development of non-conventional medicine (which in the Western world encompasses also EM therapies) in its Resolution from 1997: "Whereas a number of people in the Member States are making use of certain non-conventional medicines and therapies and it would be unrealistic to ignore this de facto state of affairs; Whereas the view, shared by a number of doctors, is increasingly widely held that different methods of treatment and different approaches to health and illness are not mutually exclusive, but can on the contrary be used to complement one another; Whereas it is important to ensure that patients have the broadest possible choice of therapy, guaranteeing them the maximum level of safety and the most accurate information possible on the safety, quality, effectiveness and possible risks of so-called non-conventional medicines, and that they are protected against unqualified individuals" (20). Later on the European Union (EU) has secured special finances for cooperation within the region, regarding research in complementary and alternative medicine field (21).

$\diamond$ In USA a major response to the growing use of complementary therapies, incl. EM methods, is the emergence of integrative medicine (called integrated medicine in Great Britain), referred to as "practicing medicine in a way that selectively incorporates elements of complementary and alternative medicine into comprehensive treatment plans alongside solidly orthodox methods of diagnosis and treatment" (22) .

$\diamond$ In the year 2000, UNESCO has inscripted the acupuncture and moxibustion into the UNESCO Representative List of Intangible Cultural Heritage of Humanity. UNESCO announced a World Acupuncture Day (15 th of Nov. 2018) and a World Scientific and Cultural Dialogue on Acupuncture in order to commemorate the $8^{\text {th }}$ anniversary of this fact.

$\diamond \mathrm{WHO}$ has edited Benchmarks for training in TCM (23). EM training is included in higher medical education curriculum in China and in other native for EM countries, like Indonesia.

$\diamond$ There is a growing interest among the international research community towards outcome assessment, related to EM methods (24).

\section{National factors for EM-development}

Public health realities usually reflect the cultural, socio-economic, and political characteristics of a country. The public health system in Bulgaria is in a 
state of constant transition, which makes it unstable but also open to innovations.

$\diamond$ Currently, there are intensive debates on reforms in the financial model. Generally, public health regulations related to complementary and alternative medicine, including EM therapeutic modes, meet international standards. The statutory regulation of EM is included in the regulation of non-conventional medicine and the general EM regulations are integrated in the Health Law. Bulgarian legislation regulates the training and practicing of some methods that are part of the "unconventional methods", which include most of the TCM methods like acupressure, acupuncture, auriculum-diagnostics, and pulse diagnostics $(25,26)$.

$\diamond$ It is necessary to appreciate also that there are long-lasting traditions in herbal medicine in Bulgaria. As a whole Bulgarians are open to the traditional methods of healing (27). Contemporary ethnobotanical research proves the rich Bulgarian traditions in the use of medicinal plants (28).

$\diamond$ The EM native countries provide support and expertise in Bulgaria in regard to their traditional medicinal systems and methods (29).

Threats of the external environment for EM developments in Bulgaria

\section{International threats for EM developments}

$\diamond$ The provision of EM in Europe is patchy, which means that citizens experience non-equitable and, in some countries, limited access to EM therapies.

$\diamond$ The legal frame of EM varies from country to country in the industrialized world.

$\diamond$ There are no training standards for EM professionals. Often EM methods are not practiced by medical doctors.

$\diamond$ Very often Western medical doctors do not accept EM, because of lack of evidence-based scientific literature. The clinical studies on EM therapies use different standards and are mostly published in Chinese language.

$\diamond$ In a number of EU Member States EM practices and EM medicinal products are unregulated and may pose risks to the health and safety of patients.

\section{National threats for EM developments}

$\diamond$ Despite the advances in the international support, evidence-based research on EM therapies is at its beginning. The really significant financial tools for research are still missing.

$\diamond$ Language and cultural differences have also presented special difficulties regarding EM developments. For example, often scientific literature and training courses are in foreign languages.

$\diamond$ Attitudes towards EM professionals - there is still lack of tolerance among medical specialists, which is due to mistrust and lack of knowledge.

$\diamond$ The EM methods are not integrated in the national health insurance model, which means: not publicly funded; no relevant national data on the prevalence of use and provision of such care.

$\diamond$ The EM training is not included in higher medical education curriculum.

Round 2: Identifying Weaknesses and Strengths of the EM Domain

EM is native for the Asian continent but its use is rapidly growing in Bulgaria. Against this background we have identified the following strengths and weaknesses of the EM domain in the country.

Strengths of EM domain in Bulgaria

$\diamond$ There are traditions in acupuncture as a therapeutic method in Bulgaria. The first medical doctors have been trained in the 1960s. In 1978 an Acupuncture section was founded within the Bulgarian Society of Neurology. Bulgaria hosted the VIII World Congress of Acupuncture (Sofia, 15-20 May 1983) (30).

$\diamond$ Nowadays, there are many centers on Chinese or Eastern Medicine all over the country. The Medical University of Varna founded the first University Centre of Eastern Medicine in Bulgaria where therapy, research $(31,32)$ and training are successfully combined [the first course was organized in March 2018 on "Ayurveda Introduction and Diagnostics", Lecturer Dr. Naushad from Ayurveda and Yoga Therapy Centre in Moscow].

$\diamond \mathrm{EM}$ is nature-centered, stable and conservative (33). EM applies a holistic approach to health, 
which harmonizes with the current "Back to Nature" or "Green" trends among the younger generation in Bulgaria. EM, especially herbal $\mathrm{EM}$, revives the Bulgarian traditions in medicinal plants usage.

$\diamond$ EM helps reduce the need of antibiotics, thus reducing the problem of antimicrobial resistance.

$\diamond$ EM treatments are safe with hardly any adverse effects.

$\diamond \mathrm{EM}$ can restore the patient's energy (chi) and helps the immune system to manage the disease.

$\diamond$ There is increasing evidence for EM effectiveness and cost-efficiency.

Weaknesses of the EM domain in Bulgaria

The weaknesses of the EM domain are those attributes that may impede development and success.

$\diamond \mathrm{EM}$ bases itself on a strictly organized theory, which allows to accurately determine the manifestation of the disease but cannot always be quantified in an evidence-based frame. Western medicine is considered to be "evidencebased medicine" and applies quantitative diagnosis, on the basis of which the treatment is perfectly assigned.

$\diamond$ Health care can broadly be divided into modern (conventional, orthodox, Western or allopathic) and traditional (indigenous, complementary, alternative or integrative incl. EM). Western health care is with minor regional variations in its underlying philosophy, financial flows and clinical methods. In modern medicine, knowledge building is achieved through scientific research, which can involve global collaboration and commitment. Such research is well supported financially by industry, governments and non-governmental organizations. This is in sharp contrast to the situation with EM.

$\diamond$ Lack of EM formal academic education at the universities.

$\diamond$ Lack of trust in EM products because of lack of trust in the quality assurance processes at a national context.

Ultimately, we have now produced a simple compilation of external opportunities and threats against internal strengths and weaknesses providing useful information for the strategic formulations which are also part of Round 3: Mapping Interactions \& Strategy Classification.

Strategy Formulation as a Conclusion / Round 3: Mapping Interactions \& Strategy Classification

Western medicine, otherwise known as orthodox medicine, is the practice of healthcare that most of the Bulgarians are familiar with. This is the system in which doctors and other healthcare professionals see patients and treat their symptoms with the use of prescription medications, surgical operation, various forms of therapy and radiation. Therefore, the only sustainable public health approach for EM future developments in Bulgaria is the collaborative strategy. As Dr. Margaret Chan (former WHO Director General) stated "The two systems of traditional (incl. EM) and Western medicine need not clash... they can blend together in a beneficial harmony, using the best features of each system and compensating for certain weaknesses in each". Moreover, WHO recommends in its Strategy/2014-2023 that Traditional Medicine (including EM) should be integrated into the healthcare systems of each and every country (34). The EM methods have their place in the prophylaxis and treatment of the Bulgarian patient (8). The analysis reveals that there are both strengths and opportunities for the modern developments of EM in Bulgaria. They must, however, outweigh the weaknesses and threats to such a development. In our view, increased international collaboration, more awareness of the EM effectiveness and public health benefits shall enhance the chances of EM to be fluently integrated in the Bulgarian national health care system. Therefore, the Maxi-Maxi Comparative Advantage strategies should build on EM strengths and the evolving international and national external opportunities in order to integrate EM in the national public health system.

EM in Europe is an indivisible part of the Complementary and Alternative Medicine (CAM) paradigm (35). Another maxi-maxi strategy is the development of EM research, which proves the effectiveness, efficiency and safety of the EM methods.

A strategy on quality assurance of EM therapies is a must. EM professions should therefore be regulated, based on clearly defined qualifications and competences. EM products should comply with quality and safety standards. Moreover, the majority 
of EU citizens would like conventional medical doctors to be more supportive of and more knowledgeable about complementary medicinal methods, and have a greater role in terms of referral to such specialists and as sources of information (36). Consequently, education in EM methods needs to be included in the higher medical education curriculum.

EM is used by more and more people in Bulgaria. Strategically, EM should be included in the national public health approaches to health promotion and prevention. However, EM is currently ignored at a policy level. Therefore, the development of more outward-looking stakeholders could enhance the chances of the rapid establishment of modern schools for EM in the country. More research-based evidence is needed in order to convince those who do not trust it and to develop solid scientific grounds for sustainable public health policies related to EM.

\section{Acknowledgments:}

This article reflects decades of professional interest but is an immediate result of the author's participation in the course organized by the University Centre of Eastern Medicine (UCEM) at Medical University of Varna with the expert support of the Medical Faculty of the Tarumanegara University in Jakarta and the Pharmacy Faculty of the Indonesian International Institute for Life Sciences, Indonesia (17-28 Sept. 2018). Many thanks go to the main lecturer Dr. Fenny Yunita and to Assoc. prof. P. Mancheva, Head of UCEM! All these research developments would not have been possible without the MU-Varna leadership support for innovations and for research promotion.

\section{REFERENCES}

1. Petkov V, editor. Contemporary phytotherapy. Sofia: Medicina and Fizkultura; 1982. [in Bulgarian].

2. Dimkov P. Bulgarska Narodna Medicina. Vol. 1-23. Sofia: Bulgarian Academy of Sciences Press; 1993. [in Bulgarian].

3. Elmazov E, editor. The Best from the Vestnikkniga, V I \& II. Sofia: Emil G. Elmazov; 1994. [in Bulgarian].

4. Yordanov K, Kapincheva I, editor. Priroden Lekar. Varna: Helix Press; 2005. [in Bulgarian].

5. Frass M, Strass RP, Friehs H, Müllner M, Kundi M, Kaye AD. Use and acceptance of complementary and alternative medicine among the general popu- lation and medical personnel: a systematic review. Ochsner J. 2012;12(1):45-56.

6. Bourne L. Stakeholder relationship management: A maturity model for organisational implementation. Aldershot, UK: Gower Publishing Ltd; 2009.

7. Yunita, F. 2018. Traditional Chinese Medicine - Introduction to Acupuncture, handouts, the course was organized by Medical University of Varna, Center for Eastern Medicine and the Medical Faculty of the Tarumanegara University in Jakarta, Pharmacy Faculty of the Indonesian International Institute for Life Sciences, Indonesia. 17-28.09.2018.

8. Mancheva P. Is cooperation between Eastern and Western Medicine possible in Bulgaria? Scr Sci Salut Publicae. 2018; 4:69-73.

9. Yunita, F. 2018. Traditional Medicine in Indonesia, First Lecture of the Course "Traditional Chinese Medicine. Acupuncture”, Handouts, 17-28.09.2018.

10. Vankova D, de Leeuw E. 2001. Public health human capacity building in bulgaria - theory and application of SWOT analysis. Int J Publ Health Educ. 2001;3:18-47.

11. Bryson JM. Strategic planning for public and nonprofit organizations: a guide for strengthening and sustaining organizational achievement. 1st ed. San Francisco: Jossey- Bass;1990.

12. Casebeer A. Application of SWOT Analysis. Br J Hosp Med. 1993; 49(6):430-1.

13. Pfeffer J, Salancik R. The external control of organizations: A resource dependent perspective. Stanford Business Books; 1978.

14. Nutt PC, Backoff RW. Strategic Management for public and third sector organizations: A handbook for leaders. San Francisco: Jossey- Bass; 1992.

15. Weihrich H. The TOWS Matrix - a Tool for Situational Analysis. Long Range Planning. 1982; 15(15):54-66.

16. Kearns KP. From comparative advantage to damage control: Clarifying strategic issues using SWOT analysis. Nonprofit Management \& Leadership. 1992; 3(1): 3-22.

17. Bryson, JM. Strategic planning for public and nonprofit organizations. San Francisco: Jossey-Bass; 1995.

18. WHO. General Guidelines for Methodologies on Research and Development of Traditional Medicine, WHO: Geneva; 2000. 
19. WHO. Legal Status of Traditional Medicine and Complementary/Alternative Medicine: A Worldwide Review, WHO/EDM/TRM/2001.2, Distr.: General, English only; 2001.

20. European Parliament. A4-0075/97 Resolution on the status of non-conventional medicine; 1997.

21. CAMbrella (a pan-European research network project- 2010-2012), online repository for EU projects; 2012. Available at: http://www.cambrella.eu/ home.php?il=203\&l=deu, accessed 10.2018.

22. Faass N. Integrating complementary medicine into health systems. Gaithersburg: Aspen Publications; 2001.

23. WHO. Benchmarks for training in traditional / complementary and alternative medicine, Training in Traditional Chinese Medicine, WHO: Geneva; 2010.

24. Acupuncture research site, https://www.acupuncturetoday.com/mpacms/at/home.phpq, accessed 20.10.2018.

25. State Gazette (official edition of the National Assembly). Health law. №70/10.08.2004 in effect from 01.01.2005/ recent changes SG №18/27.02.2018 [in Bulgarian].

26. State Gazette, issue 22 from 15.III , Regulation № 7 from 1 of March 2005 About the requirements for the professionals who practice non-conventional methods for beneficial impact on individuals health; changes in NG 24 from 31 of March 2009.

27. Kozuharova E, Lebanova H, Getov I, Benbassat N, Napier J. 2012. Descriptive study of contemporary status of the traditional knowledge of medicinal plants in Bulgaria. Afr J Pharm Pharmacol. 2012; 7(5):185-98.

28. Nedelcheva A. 2011. Medicinal plants from an old Bulgarian medical book., J Med Plant Res. 2011;6(12):2324-39.

29. China Embassy. Traditional Chinese Medicine, http://www.chinaembassy.bg/bjly/kjwh/1/t139097. htm, accessed 10.2018.

30. Ispirka S. 2009. Acupuncture Development in Bulgaria. In: Sources, historiography and methodology of history of medicine research. Varna Society of History of Medicine; 2009. pp 34-8.

31. Shivachev Y, Stancheva E, Mancheva P. Eastern medicine in management of chronic disk disease. Health Econ Manag. 2017;2(64):36-9. [in Bulgarian].
32. Nenova G, Mancheva P, Kostadinova T. Satisfaction of patients with arthrosis from multidsciplinary cooperation. J IMAB. 2016; 22(4):1338-43.

33. WHO. Legal Status of Traditional Medicine and Complementary/Alternative Medicine: A Worldwide Review - 2001; 2001. Available from:

34. http://apps.who.int/medicinedocs/en/d/ Jh2943e/3.3.html.15.10.2018.

35. WHO. Traditional Medicine Strategy 2014-2023, 2013. WHO: Geneva; 2013.

36. Kapincheva I, Vankova D. Pan-European concept "Complementary and Alternative Medicine" (CAM) - history, content and public health importance. Soc Med. 2018; 2:18-22.

37. Nikolai T. Overview of CAM therapies in Europe. Workshop "Complementary and alternative therapies for patients today and tomorrow", European Parliament, 16 October 2017. 